\title{
Promise Approach on Chemical Stability Enhancement of Papain by Encapsulation System: A Review
}

\author{
Chandan Channamade ${ }^{1}$, Jeyaprakash Mari Raju, ${ }^{1, *}$, Sushma Basavaiaha Vijayaprakash ${ }^{2}$, Rinchi Bora ${ }^{1}$, Nunavath Raja Shekhar ${ }^{1}$ \\ 'Department of Pharmaceutical Analysis, JSS College of Pharmacy, JSS Academy of Higher Education and Research, Ooty, The Nilgiris, Tamil Nadu, INDIA. \\ 2Department of Nutrition and Dietetics, Faculty of Life Science, JSS Academy of Higher Education and Research, Mysuru, Karnataka, INDIA.
}

\begin{abstract}
Papain a proteolytic enzyme is one of the enzymes which have various applications in regard to the food and chemical industry. Papain is isolated by cutting or making incision on the unripe fruit of papaya. Papain enzyme is more active in unripe green fruit. Papaya contains a papain enzyme which will be more helpful in treating the causes of trauma, allergies and sports injuries also papain has a superior digestion action when compare to pepsin and pancreatin. Papain is used variously in textile, pharmaceutics and cosmetics. The papain is extracted from the latex of papaya which is a major chemical compound used in various industries for numerous pharmaceutical and industrial products. Researchers interest towards the enzymes including papain enzyme and it health benefits is favorable. Fusion of papain in various food systems, it has its own stability issues which concerns in deactivate or denature of papain enzyme when it comes in contact with acidic $\mathrm{pH}$ inside the body. Several mechanical and chemical processes based on encapsulation techniques have emerged
\end{abstract}

that have been tailored to suit the encapsulation of various food bioactive compounds. Therefore, in order to protect the nature of papain enzyme, Encapsulation/ Formulation has been proposed as an option. After the Encapsulation/ Formulation is done the enzyme will improves its stability issues, maximum therapeutic potential, and also helps in the oral bioavailability and effective oral delivery of the Papain enzyme.

Key words: Papain, Stability, Bioavailability, Encapsulation, Formulation.

Correspondence

Dr. MR Jeyaprakash

Assistant Professor, Department of Pharmaceutical Analysis, JSS College of Pharmacy, Ooty, The Nilgiris-643001, Tamil Nadu, INDIA.

Email: jpvis7@jssuni.edu.in

DOI: 10.5530/jyp.2021.13.20

\section{INTRODUCTION}

In the era of the twenty-first century, the industries and the researchers are more spreading their attention towards the commercialization of enzymes, vitamins, proteins, etc. Concerning that, commercialization of enzymes is the most simple, convenient, and economical in the different industrial procedures. Papain is one of the enzymes which have varied applications in the food and chemical industry. Papain is rich in the unripe papaya (Carica papaya). ${ }^{1}$ Vitamin $\mathrm{A}, \mathrm{C}$, and $\mathrm{E}$ are three influential antioxidant sources that are rich in Papaya; Vitamin B, pantothenic acid and foliate and fiber; and some minerals, magnesium, and potassium. In Cardiovascular system improvement, to defensive action towards heart diseases, heart attack strokes and to avoid the colon cancer whole nutrients of papaya are helpful.

Additionally, Papaya contains a proteolytic enzyme that will more helpful in treating sports injuries, allergies, and causes of trauma. ${ }^{2}$ Papain is isolated by cutting or making an incision on the unripe fruit of papaya. Papain enzyme is more active in unripened green fruit. ${ }^{3}$ Proteolytic activity is carried out by Papain and it belongs to the family cysteine proteinase. The literature has been well described the Proteolytic activity of papain which also includes the Proteoglycans and elastin degradation. ${ }^{4}$ A proteolytic enzyme, Papain (E.C 3.4.22.2) molecular mass of 23,406 consist of a 212 amino acids polypeptide chain. Papain is used variously in textile, pharmaceutics, and cosmetics, and food industries. ${ }^{5}$ Papain has a superior digestive action when compared to pepsin and pancreatin which has been explained by Dr. John and Whitman Ray. In 2003, Papain is generally from the latex of papaya which is a major chemical compound used in various industries for numerous pharmaceutical and industrial products. This review focuses principally on two aspects.
Firstly, on understanding the morphological properties and chemistry of papain, stability issues, and the health benefits regarding the papain enzyme, and secondly on how it can preserve and the encapsulation aspects in storing and commercialization of the papain enzymes. This is the complete review on the papain that endeavors to take part in so many aspects of enzyme commercialization. This study has been done to gather information about the papain enzyme and its encapsulation aspects to backlog the enzyme manufacturing industry in scenarios for the new applicants.

\section{PAPAIN ENZYME}

In 1873, Papain action was first investigated and Publishes an article entitled "The solvents Action of Papaya Juice on Nitrogenous Articles of Food" in Calcutta Medical Journal by G. C. Roy. In the 19th century, Papain was first named by Wurtz and Bouchut, and they did partial purification of the product from papaya sap. Proteolytic activity in the Papaya latex of tropical region was recognized when it was the first named. ${ }^{6}$ The geometry of the active site was reviewed and the 3-dimensional structure was determined to a 1.65 Angstrom resolution in 1980s. In the 1990s, the inhibitors and precursors were studied.

\section{About the Structure of Papain}

Papain consists of 212 AA with a molecular weight of $23,406 \mathrm{Da}$. It is a single-chain protein with 4 disulfide bridges and with important catalytic residues in the following positions i.e. Gln 19, Cys25, His 158, and His $159 .^{8,9}$ Table 1 shows the amino acid composition of the papain. Papain is a cysteine hydrolase that is very stable even at elevated temperatures and 
also active under a wide range of conditions. ${ }^{10}$ Denaturing agents in high concentrations are remarkably rebellious for papain, Such as organic solvent like $70 \%$ Ethanol or $8 \mathrm{M}$ urea. Papain may vary with different substrates but has optimum $\mathrm{pH}$ in the range of 3.0-9.0. ${ }^{11}$

Two well-defined domains of papain are the best system to understand the folding and unfolding behavior of proteins. ${ }^{12}$ The protein stabilized by 3 disulfide bridges in which the molecule along with bridges creates a strong interaction among the side chains which is dependent on the stability of enzyme. ${ }^{11,3}$ Papain consists of 2 distinct structural domains with a cleft between them within its 3-dimensional structure. The cleft contains a catalytic diad that has been comparing to the catalytic triad of chymotrypsin and also cleft contains an active site in it. With the AAs Cysteine-25 and Histidine-159, Catalytic diad is made of. Aspartate-158 was supposed to play an analogous role of aspartate in the serine protease catalytic triad, but that had been invalidated. ${ }^{13}$

\section{STORAGE/ STABILITY}

$10 \mathrm{mg} / \mathrm{ml}$ amount of papain is soluble in water. Buffer containing $5 \mathrm{mM}$ L-cysteine can typically dilute the papain enzyme. Its stabilizing or activation agents include Dimercaptopropanol, Cysteine, and EDTA. ${ }^{14}$ Papain activity can be maintained after the re-crystallization in $8 \mathrm{M}$ urea solution or $70 \%$ methanol and also papain enzyme are stable to some of the denaturing agents. Papain should be stored at $2-8^{\circ} \mathrm{C}$. Meanwhile, papain solution is $\mathrm{pH}$-dependent and also has good temperature stability. Under acidic conditions i.e., below $2.8 \mathrm{pH}$ value, Papain solutions are unstable and also a substantial decrease in the activity. ${ }^{15}$ There is a loss of activity of about 1-2\% per day for an active enzyme solution which possibly results in autolysis and/or oxidation.

\section{PAPAIN USES IN VARIOUS FIELDS}

The research reported that in chemical excavation for dentin, Papainbased gel has been used. ${ }^{16}$ In chemo-mechanical dental carries removal papain is also used and it does not restrict in both strength of restorative materials to dentin. ${ }^{17}$ Papain enzyme has a long history of treating the causes of trauma, allergies, and sports injuries. ${ }^{18}$ Favorably Papain has been recognized as notable benefits for use of papain protease in the case of sports injury with the clinical evidence. Earlier has been testified that the use of papain protease will heal faster minor injuries instead than placebos. Likewise, the curing time of a cut is been reduced from

Table 1: Papain enzyme's AA Composition.

\begin{tabular}{cccc} 
AA & No & AA & No \\
\hline Lysine & 10 & Glycine & 28 \\
Histidine & 2 & Alanine & 14 \\
Arginine & 12 & Valine & 18 \\
Aspartic acid & 7 & Isoleusine & 12 \\
Asparagine & 12 & Leusine & 11 \\
Glutamic & 8 & Tyrosine & 19 \\
Acid & 12 & Phenylalanine & 4 \\
Glutamine & 8 & Tryptophan & 5 \\
Threonine & 13 & Cysteine & 1 \\
Serine Proline & 10 & Half cysteine & 6 \\
\hline
\end{tabular}

8.4 days to 3.9 days in who the athletes who are consuming the papain protease supplements. ${ }^{18,19}$ Papain is used to overcome the diseases like hypochlorhydria, leaky gut syndrome, and intestinal symbiosis like gluten intolerance. They have reported that papain has substantial anti-inflammatory and analgesic activity against symptoms of acute allergic sinusitis like toothache pain and headache without side effects. ${ }^{20}$ Likewise, papain is used in Antihelmintic, cures diarrhea, relieves dyspepsia, the pain of burns and topical use, whooping cough, and bleeding hemorrhoids. ${ }^{21}$

The main proteins which are responsible for tenderness are myofibrillar and connective proteins that are the reason papain is utilized in the tenderness of the meat. A commonly used ingredient in the brewery and meat processing is the papain. ${ }^{22}$ Papain has application in both hide tanning and fur because to ensure the uniform dying of the leather and also actions in the clarifying agent in the food industry. In fighting against dyspepsia, digestive disorders, and disturbance in the digestive tract papain is used as a protein digestant. ${ }^{15}$ In Pharmaceutical preparations, Papain has been procured to produce high-quality Kunafa, Pastries, and other local sweets. Gel-based papain enzyme will show Antibacterial, Anti-inflammatory, and Antifungal properties. ${ }^{23}$

Carica papaya is an herbaceous plant having self-supporting stems which are found in tropical and different sub-tropical regions of the world. Carica papaya plant is the main source of the Papain enzyme..$^{24}$ Likewise, Papaya is available almost all over the year because there is no limitation due to seasonality. Thus, there is no need to assist the agriculturalists or industrialists in the production of papaya and the significance of planning a unit of papain. It is reported that $8.17 \mathrm{~g}$ is the higher papain yield per fruit and $686.29 \mathrm{~g}$ is the highest papain yield per plant in 6 months in a well-managed Papaya production unit. ${ }^{25,26}$ Industries like breweries, food, detergents, pharmaceuticals, leather, and preserving meat and fish, Papain is used in various processes. Subsequently, there are several good scenarios for Papaya farming, papaya production, Extraction of papain, and Papain marketing which will be the key source of income for small-scale farmers.

\section{ENCAPSULATION ASPECTS}

To utilize the papain in medical or in the pharmaceutical within foods and medicine is limited from several factors i.e. chemical instability, low bioavailability, and instability issues towards $\mathrm{pH}$. Under acidic conditions, Papain solutions are unstable i.e., $\mathrm{pH}$ of below 2.8. It leads to a substantial decrease in the activity of the enzyme.

To utilize the papain and prevent the activity of the papain in $\mathrm{pH}$ conditions, Encapsulation is a key tool for it. ${ }^{27}$ A process by which we can entrap one substance (active agent) within another substance (wall material), is defined as Encapsulation. The substance used for encapsulation is called core or active. When the encapsulation is done, they can name frequently as a shell, capsule, external phase or matrix, carrier material..$^{28,29}$

In utmost cases, a bioactive component is fully covered, protected, and enveloped by a material, without any outcrop of the bioactive components is referred to as Encapsulation technology. ${ }^{30}$ Correspondingly, packing of materials or bioactive components in small capsules helps in controlled release rate over a sustained period under specific conditions is also epitomize Encapsulation technology. In the improved delivery of the bioactive molecules (minerals, vitamins, lutein, enzymes, and fatty acids) and living cells into food, Encapsulation plays a vital role. ${ }^{28,30}$ Encapsulation can be functional for the alteration of physical characteristics of the original material to:

a) Handling will be easier

b) Aids in separating the components of the mixture or else it will mix 
c) To deliver an acceptable concentration and constant dispersion of an active agent. ${ }^{31}$

Consequently, Encapsulation will also help in the improvement of stability and bioavailability, handling of a product, and in developing the product for supplementation and food fortification. Encapsulation is a technique where you can form a coating or wall material to the sensitive ingredients. $^{32}$

For the encapsulation of papain, there are different methods for appropriate delivery system, i.e. sodium alginate beads, microspheres; enteric coating, Nanofibers, solid lipid nanoparticles, oil-water emulsion, and complex associated with macromolecules are reported. Depending upon the methods equipped the effectiveness of Encapsulation depends. ${ }^{33}$ Water activity, moisture content, the morphology of microcapsules, particle size, and encapsulation efficiency will be affected by the method which is equipped. Oil-in-water nanoemulsions are the most effective and economical way to increase the stability and bioavailability of nutraceuticals. Despite having enhanced thermal stability, Nanoemulsions are also susceptible to environmental stress, and also encapsulated compounds can be subverted when there is an alternation in the $\mathrm{pH}^{34}$

To preserve the activity and improve the stability of the papain, the Encapsulation process needs to be done. Research conducted by Shushil et al. 2008 explains an outline about the influence of sodium alginate beads on entrapment efficiency, results show that when papain is coated with the alginate beads increases with sodium alginate concentration; although, when calcium chloride concentration increases it will be affected. Meanwhile, dissolution studies for the papain-coated alginate beads for site-specific intestinal delivery are explained. ${ }^{35}$ In contrast, Manu Sharma et al. 2011 reported that enteric formulations using microspheres possibly will aid as a potential carrier for an oral delivery of papain to ease the digestion of peptides/proteins. ${ }^{36}$

On the other hand, Manu Sharma et al. 2011 reported that enteric formulations using HPMC Phthalates, Eudragit L100, and Eudragit S100 particles have great potential as oral delivery of papain to enable the digestion of proteins in small and large intestine. ${ }^{37}$ According to Shoba E et al. 2012, in the preparation of PVA nanofibers loaded with Papain/ Urea, there will be low encapsulation efficiency when papain and urea concentration was increased by more than $30 \mathrm{wt} \%$ of papain and $15 \mathrm{wt} \%$ of urea. ${ }^{38}$ The research reported by Suriyakala et al. 2018 explains that in the preparation of solid lipid nanoparticles for the papain Cetyl alcohol not only acting as a carrier but also acts as a surfactant to influence the drug entrapment into lipid nanoparticles system. ${ }^{39}$ Chankhampan et al. 2012 investigated that Papain-loaded PLGA nanospheres, Papain PLGA nanospheres with loaded papain shows higher chemical stability than papain in a solution of eight and three times when kept for 6 weeks at $4^{\circ} \mathrm{C}$ and $25^{\circ} \mathrm{C} .{ }^{40}$ As of all the research studies done on the encapsulation of papain can conclude that to stabilize the activity of the enzyme and to overcome the instability in stomach $\mathrm{pH}$ more research works have to be done. So with the intention of a suitable carrier delivery system and to increase therapeutic potential we can adopt an encapsulated papain enzyme which is improved in its stability issues and also oral bioavailability.

\section{CONCLUSION}

Papaya, widely familiar as a food artifact, has an enormous diversity of components with extraordinarily miscellaneous configuration. A noteworthy quantity of experiments on its biological activity has been executed, as well as their favorable applications. It validates astounding levels of frequently mentioned nutritional characteristics. Hence, a widespread examination of its proper standardization, kinetics, pharmacodynamics properties, as well as clinical trials is directly desirable to exploit its therapeutic efficacy and effectiveness to fight in contradiction of innumerable difficulties and get the better of deficiency symptoms. Owing courtesy should be paid to its functional, nutraceutical, and medicinal assets; its food therapy for prevention and cure of various difficulties and disorders.

The health-stimulating properties of Papain from the Carica papaya fruit have acquired the consideration of industrialists and researchers. The price of the natural resources from papaya fruit can be abridged by reclaim the waste part of the fruit from food processing and encapsulating it with suitable encapsulation materials. The revised food processing and extraction technology must also confirm the slightest oxidization and isomerization of papain. Quantification and exploration techniques promise reliable results with high accuracy and precision. Papain will be a recipe that shows activities like high antioxidant capacity, stability, and bioavailability which will get high priority. There are frequent and unexplored possibilities for the Papain analysis where superior consideration should be given to search for economical natural resources, which are obtained from the waste part of the Papaya. This would potentially meet the demand of people that lack a proper diet as well as elder people with chewing problems, especially in the rural areas. In conclusion, different extracted parts of the papaya fruit continue to be used in herbal medicine practice for the treatment of chronic or acute diseases, viral pathologies, and immune modulators. So, therefore, it is safe to guess that the Papain encapsulation/formulation would be helpful to mankind.

This review article proposes that Papain will have its stability issues. Concerns about the stability of the enzyme there is the loss of activity. The enzyme will deactivate or denature when in contact with the acidic $\mathrm{pH}$ inside the body. Their deactivation will lead to a loss of their purpose. Therefore, to protect the nature of the enzyme nature, encapsulation/ formulation has been proposed as an option. When the bioactive compounds are encapsulated, their physicochemical properties will be preserved in different $\mathrm{pH}$ conditions, which help in reaching their target.

\section{ACKNOWLEDGEMENT}

I consider it as my honour to acknowledge my sincere thanks to JSS College of Pharmacy, Ooty for the help and support throughout this work. It is my privilege to express my extreme sense of gratitude for extending facilities and providing constant support throughout this work.

\section{CONFLICT OF INTEREST}

The authors declare no conflict of interest.

\section{ABBREVIATIONS}

E. C: Electronic Configuration; A A: Amino Acid; Da: Dalton; EDTA: Ethylene di amine tetra acetic acid; HPMC: Hydroxy propyl Methyl Cellulose; PLGA: Poly lactic co glycolic acid; Gln: Glutamine; Cys: Cysteine; His: Histamine.

\section{REFERENCES}

1. Brocklehurst K, Baines BS, Kierstan MP. Papain and other constituents of Carica papaya L. Enzyme Ferment. Biotechnol. 1981;5(5):262-35.

2. Gurditta PM. Basket full benefits of papaya. Int Res J Pharm. 2011;2(7):6-12

3. Tsuge H, Nishimura T, Tada Y, Asao T, Turk D. Inhibition mechanism of Cathepsin Lspecific inhibitors based on the crystal structure of papain- CLIK148 complex. Biochem Biophys. 1999;266(2):411-6.

4. Chaudhari R. Macroscopic and microscopic evaluation of Carica papaya I. Leaves. Herbal drug industry. Eastern Publishers. New Delhi. 1996;45-78.

5. Thomás GE, Rodolfo HG, Juan MD, Georgina SF, Luis CG, Ingrid RB, et al. Proteolytic activity in enzymatic extracts from Carica papaya L. cv. Maradol harvest by-products. Process Biochemistry. 2009;44(1):77-82. 
6. BouchutW. Proteolytically active constituent in the latex of tropical papaya fruit. 1945.

7. Vernet $T$, et al. Processing of the papain precursor. J. Biological Chemistry. $1991 ; 270(18): 10838-46$.

8. Mitchel RE, Claiken MI, Smith ELJ. The complete amino acid sequence of papain. J Biol Chem. 1970;245(14):3485-92.

9. Alecio MR, Dann ML, Lowe G. The specificity of the $S^{\prime} 1$ subsite of papain. J Biochem. 1974;141(2):495-501. PMID: 4455218

10. Cohen LW, Coghlan VM, Dihel LC. Cloning and sequencing of papain-encoding cDNA. Gene. 1986;48(2-3):219-27.

11. Edwin F, Jagannadham MV. Single disulphide bond reduced papain exists in a compact intermediate state. Biochem Biophys Acta. 2000;1479(1-2):69-82.

12. Ghosh S. Physicochemical and conformational studies of papain/sodium dodecyl sulfate system in aqueous medium. J Colloid Surf A: Phys Eng Aspects. 2005;264(1-3):6-16.

13. Menard R, Khouri HE, Plouffe C, Dupras R, Ripoll D, et al. A protein engineering study of the role of aspartate 158 in the catalytic mechanism of papain. Biochemistry. 1990;29(28):6706-13.

14. Arnon R. Papain. Meth Enzymol. 1970;19:226-44.

15. Huet J, LoozeY, Bartik K, Raussens V, Wintjens R, et al. Structural characterization of the papaya cysteine proteinases at low $\mathrm{pH}$. Biochem Biophysical Res Commun. 2006;341(2):620-6.

16. Piva E, Ogliari FA, Moraes RD, Cora F, Henn S, et al. Papain-based gel for biochemical caries removal: Influence on micro tensile bond strength to dentin. Braz Oral Res. 2008;22(4):364-70.

17. Lopes MC, Mascarini RC, DeSilva BM, Florio FM, Basting RT. Effect of a papainbased gel for chemo mechanical caries removal on dentin shear bond strength. J Dent Child. 2007;74(2):93-7.

18. Dietrich RE. Oral proteolytic enzymes in the treatment of athletic injuries: A double-blind study. Pennsyl Med J. 1965;68(10):35-7.

19. Trickett P. Proteolytic enzymes in treatment of athletic injuries. Appl Ther. 1964;6:647-52.

20. Mansfield LE, Ting S, Haverly RW, Yoo TJ. The incidence and clinical implications of hypersensitivity to papain in an allergic population, confirmed by blinded ora challenge. Ann Allergy. 1985;55(4):541-3.

21. Arvind G, Bhowmik D, Duraivel S, Harish G. Traditional and medicinal uses of Carica papaya. J Med Car Pap. 2013;1(1):2320-3862.

22. Khanna N, Panda PC. The effect of papain on tenderization and functional properties of spending hen meat cuts. Indian J Anim Res. 2007;41(1):55-8.

23. Anthoni C. Antifungal effects of pawpaw seed extracts and papain on postharvest Carica papaya L. fruit rot. Afri J Agri Res. 2010;5(12):1531-5.

24. Jaime A, Teixeira S, Zinia R, Duong TN, Dharini S, et al. Papaya (Carica papaya L.)
Biology and biotechnology. Tree Forest Sci Biotechnol. 2007;1(1):47-73.

25. Kumar KR, Amutha R, Muthulaksmi S, Mareeswari P, Rani WB. Screening of Dioecious papaya Hybrids for Papain Yield and Enzyme Activity. Res J Agric Biol. 2007;3(5):447-9.

26. Reddy SR, Krishna RB, Reddy KJ. Sex determination of Papaya (Carica papaya) at seedling stage through RAPD Markers. Res Biot. 2012;3(1):21-8.

27. Sutter SC, Buera MP, Elizalde BE. $\beta$-Carotene encapsulation in a mannitol matrix as affected by divalent cations and phosphate anion. Int J Pharm. 2007;332(12):45-54.

28. Zuidam NJ, Nedovi VA. Encapsulation Technologies for Food Active Ingredients and Food Processing, Springer: Dordrecht, The Netherlands. 2010;31-100.

29. Fang Z, Bhandari B. Encapsulation of polyphenols: A review. Trends Food Sci Technol. 2010;21(10):510-23.

30. Kashappa DGH, Park HJ. Recent developments in microencapsulation of food ingredients. Drying Technol; An Int J. 2005;7(23):1361-4.

31. McClements $D$, Lesmes U. Structure-function relationships to guide rational design and fabrication of particulate food delivery systems. Trends Food Sci Technol. 2009;20(10):448-57.

32. Loksuwan J. Characteristics of microencapsulated $\beta$-carotene formed by spray drying with modified tapioca starch, native tapioca starch and maltodextrin. Food Hydrocolloids. 2007;21(5-6):928-35.

33. Donhowe EG, Flores FP, Kerr WL, Wicker L, Kong F. Characterization and in vitro bioavailability of $\beta$-carotene: Effects of microencapsulation method and food matrix. LWT_Food Science and Technology. 2014;57(1):42-8.

34. McClements DJ. Food emulsions: Principles, practices and techniques ( $2^{\text {nd }} \mathrm{Ed}$.) Boca Raton, FL: CRC Press; 1999

35. Shushil DU, Bhaskar TN. The Purification, Formulation and Drying of Papain. Int $\mathrm{J}$ of Food Engineering. 2008;4(4):8-10.

36. Manu S, Vinay S, Amulya KP, Dipak K M. Enteric Microsphere formulations of papain for oral delivery. Int J Nanomedicine. 2011;131(5):697-709.

37. Manu S, Vinay S, Amulya KP, Dipak KM. Development of enteric submicron particle formulation of papain for oral delivery. Int J Nanomedicine. 2011;6:2097111.

38. Shoba E, Lakra R, Kiran MS, Korrapati PS. Design and development of Papain/ Urea loaded PVA nanofibers for wound debridement. J RCS Advances. 2012;13.

39. Chandran SP, Nachimuthu K. Formulation and Characterization of Papain loaded Solid Lipid Nanoparticles against human colorectal adenocarcinoma cell line. Asian J Pharm Clin Res. 2018;11(10):393-9.

40. Chankhampan C, Manosroi J, Yamamoto H, Tahara K, Manosroi W, Kawashima $Y$, et al. Chemical stability enhancement and cytotoxicity reduction of papain loaded in PLGA nanospheres. J Experimental Nano Science. 2014;2(9):138-51.

Article History: Submission Date : 04-03-2021; Revised Date : 23-04-2021; Acceptance Date : 17-05-2021.

Cite this article: Chandan C, Jeyaprakash MR, Sushma BV, Bora R, Shekhar NR. Promise Approach on Chemical Stability Enhancement of Papain by Encapsulation System: A Review. J Young Pharm. 2021;13(2):87-90 